\title{
A Study of Blood Transfusion in Pediatric Patients at a Teaching Hospital, Aden, Yemen
}

This article was published in the following Dove Press journal:

International Journal of Clinical Transfusion Medicine

\author{
Abdul-Wahab M Al-Saqladi $\left(\mathbb{D}^{1,2}\right.$ \\ Tarneem A Albanna ${ }^{2}$ \\ 'Pediatric Department, Faculty of \\ Medicine and Health Sciences, University \\ of Aden, Aden, Yemen; ${ }^{2}$ Pediatric \\ Department, Al-Sadaqa General Teaching \\ Hospital, Aden, Yemen
}

Background: Blood transfusion is an essential supportive therapy, used over a wide variety of clinical circumstances. Patterns of blood transfusion in pediatric patients are less characterized, and in Yemen information is chronically lacking. This study was aimed to assess the use of blood transfusion in children at a single center in a low resource setting.

Materials and Methods: A descriptive, cross-sectional study was conducted on all children $(\leq 16$ years) who received blood transfusion in the Pediatric Department, Al-Sadaqa Teaching Hospital, Aden, Yemen over a time period of seven months. Data on age, gender, indications, type of blood product transfused, and adverse reactions were collected.

Results: There were 360 transfusion episodes given to 202 patients, at a ratio of 2.3 transfusions per patient. The average age of transfused children was $5.63 \pm 4.63$ years and $63.4 \%$ were male. Children $\leq 5$ years comprised $50 \%$ of recipients. Single transfusion was most common (56.7\%). Major indications were hemoglobinopathies $(43.6 \%)$, and oncologic diseases $(25.3 \%)$. The overall mean of pretransfusion hemoglobin $(\mathrm{Hb})$ was $6.7 \pm 2.3 \mathrm{~g} / \mathrm{dL}$, varying by primary diagnosis, and the average $\mathrm{Hb}$ increment was 1.4 $\mathrm{g} / \mathrm{dL}$. The main types of transfused blood were red blood cell concentrates $(58.9 \%)$ and whole blood (26.4\%). Blood group O Rhesus D positive was the most requested (57.5\%), followed by A positive $(21.9 \%)$. Adverse transfusion reactions occurred in $4.4 \%$, including febrile nonhemolytic (56.2\%), allergic (37.5\%) and transfusionassociated dyspnea $(6.3 \%)$.

Conclusion: Blood transfusion is a frequent supportive therapy in pediatric patients with various medical illnesses in this population. Most common indications were hemoglobinopathies and oncologic diseases. Regular review of blood transfusion is fundamental to ensure better and more rational use of this precious resource.

Keywords: transfusion, anemia, child

\section{Introduction}

Blood is a vital human tissue and a precious health resource, required to be adequately available, safe, correctly and rationally used and timely administered. ${ }^{1}$ Blood transfusion is an essential component of modern health-care systems and when used appropriately, it saves lives, improves health conditions and enhances patient outcomes. However, improper or unnecessary use can increase the risk of serious, acute, and delayed adverse complications, and in underprivileged settings it places further strain on already limited health resources. ${ }^{2,3}$ In recognition of its critical role in the patient management over a wide variety of medical conditions, blood and blood products are currently incorporated into the World Health Organization (WHO) model list of essential medicines. ${ }^{4}$
Correspondence: Abdul-Wahab M AlSaqladi

Department of Pediatrics, Faculty of

Medicine and Health Sciences, University

of Aden, PO Box 6032, Khormaksar,

Aden, Yemen

Tel/Fax +967(2)384260

Email asaqladi@yahoo.com
International Journal of Clinical Transfusion Medicine 2021:9 I-9

(c) (i) (2) 202I Al-Saqladi and Albanna. This work is published and licensed by Dove Medical Press Limited. The full terms of this license are available at https://www.dovepress. BY $\mathrm{NC}$ com/terms.php and incorporate the Creative Commons Attribution - Non Commercial (unported, v3.0) License (http://creativecommons.org/licenses/lby-nc/3.0/). By accessing the work you hereby accept the Terms. Non-commercial uses of the work are permitted without any further permission from Dove Medical Press Limited, provided the work is properly attributed. For permission for commercial use of this work, please see paragraphs 4.2 and 5 of our Terms (https://www.dovepress.com/terms.php) 
Access to safe and adequate blood supply remains a public health challenge in many countries, particularly in low resource settings (poor economics). In high-income countries the average donation rate is $32.1 / 1000$ population in comparison to $4.6 / 1000$ population in low income countries, where about $80 \%$ of the world's population lives and has access to only $20 \%$ of the world's safe blood supply. ${ }^{5,6}$ A significant disparity also exists on regional levels, in the Eastern Mediterranean Region, Yemen was reported to have the lowest supply of blood, with an annual donation rate of $0.7 / 1000$ population, compared to $29 / 1000$ population in Lebanon. ${ }^{7}$ This variation indicates a serious inequality and is far below the proposed WHO estimates of 10 to 20 whole blood donations per 1000 population. However, a recent estimate suggested that the WHO target is even inadequate to fulfill blood requirement in the vast majority of low-income countries and the donation rates need to be increased several-fold. ${ }^{8}$

In the Middle Eastern Region which is consisting of heterogeneous countries with different levels of development, the demand for blood transfusion is on the rise as a result of increased accessibility to more advanced medical and surgical procedures, expansion of aging population, and in children there is high prevalence of transfusion dependent $\beta$-thalassemia and sickle cell disease. ${ }^{9}$ Beside the efforts for strengthening the infrastructure and testing for transfusion transmissible infections, regular documented clinical review plays a vital role in monitoring and evaluation of clinical transfusion practices, optimization of blood use and consistent adherence to guidelines and standard operating procedures. ${ }^{10}$

Children are the main users of blood, and in resourcelimited-settings they account for a high proportion of blood usage (16-67\%), compared to about 5\% reported from developed countries. ${ }^{11,12}$ Moreover, pediatric transfusion has unique aspects and is different from adults in relation to transfusion decisions, indications, doses, and frequency of adverse reactions, and this should be taken into consideration when evaluating clinical blood transfusion in this age group. ${ }^{13,14}$

Data on usage and pattern of blood transfusion is critical in order to promote rational use and this might help to conserve this scarce resource, especially in lowincome settings where the gap between need and demand exists and blood requirement is highly unmet. ${ }^{15}$

There is a paucity of information about blood usage and characteristics of recipients in Yemen, particularly among children. Therefore, the main aim of this study was to assess frequency and pattern of blood transfusion among children admitted to the pediatric medical department at a teaching hospital in Aden, South Yemen.

\section{Materials and Methods Study Design}

This is a cross-sectional, descriptive study of all children who received blood transfusion in the pediatric medical department, at Al-Sadaqa General Teaching Hospital, during a period of seven months (September 2014 to March 2015).

\section{Study Subjects}

The study included all children between the age of four months and 16 years, who were admitted because of medical reasons and received blood transfusion as part of their clinical care during the study period. Those who were under four months of age were excluded from the study, because their transfusion indications and requirements are different.

\section{Setting}

The study site was the Pediatric Department in Al-Sadaqa Teaching Hospital, which is the main pediatric and maternity hospital in Aden, South Yemen. This hospital is a public health facility serving people from Aden and adjacent governorates, including urban, suburban and referrals from nearby rural areas. The Pediatric Department consists of seven sub-departmental wards according to specialty care (hematology, oncology, gastroenterology, general, isolation, neonatal care, and ICU), and an emergency department. Six wards were included in the study, while the neonatal care unit was excluded. The entire pediatric blood transfusions in our hospital are performed in the in-patient setting, and none in the emergency department. In almost all circumstances blood collection depends on replacement, apparently nonremunerated and almost all replacement donors were recruited by patients' relatives. Screening for HIV, HBV, HCV were carried out routinely in our hospital blood bank on each blood donation, and reactive donations for the aforementioned infections were excluded.

\section{Data Collection}

Data was collected by direct interview with the closest caretaker of the child, in most instances the mother or both parents. Information was also gathered through observation and extraction of data from patient records, as soon as 
transfusions were completed. Relevant information was extracted to a standardized data abstraction form for each patient, and the following variables were noted: age, sex, dose, number, and indication for transfusion, type of blood and blood components, location of transfusion, adverse reactions and clinical outcome. Transfusion decision was based on the level of hemoglobin $(\mathrm{Hb})$ in most instances and the clinical status of the patient as well as the patient's primary disease. Transfusion episodes were considered as all transfusions given to the child during one hospital admission.

Laboratory data included were levels of $\mathrm{Hb}$, hematocrit (Hct) and platelets before and after transfusion, blood groups $\mathrm{ABO}$ and Rhesus D were also recorded. Changes of hemoglobin levels were used to calculate the difference between post and pretransfusion $\mathrm{Hb}$ to estimate red blood cell (RBC or whole blood) transfusion efficacy.

\section{Ethical Clearance}

The study protocol was reviewed and approved by the Institution Ethics Committee of the Faculty of Medicine and Health Sciences, University of Aden; permission was also obtained from the hospital administration where the study was conducted. The Institution Ethics Committee accepted verbal informed consent, after full explanation of the study purpose, safety, lack of risk, and the right of free participation. Agreement to participate was taken by verbal consent from parents/guardians for all enrolled children due to the high incidence of illiteracy. Anonymity and confidentiality of information was strictly maintained. This study was conducted in accordance with the principles of the Declaration of Helsinki.

\section{Statistical Analysis}

Data analysis was performed using the statistical package for social science (SPSS) version 20 (IBM Corporation, Armonk, NY, USA). Categorical data were expressed as frequencies (numbers and percentages) and numerical data were expressed as mean \pm standard deviation for normally distributed data or median and interquartile range for nonparametric data. Student's $t$-test was used to compare means and Kruskal-Wallis test for nonparametric data. Chi-square test was applied for comparison of categorical variables. A $p$-value of $<0.05$ was considered significant.

\section{Results}

Of the 2297 admitted children during the study period, 202 patients $(8.8 \%)$ received supportive blood transfusion therapy as part of their clinical care. Among these, 128 (63.4\%) were male and $74(36.6 \%)$ female, giving a male:female ratio of 1.72:1 $(p=0.001)$. The overall mean age of transfused children was 5.63 \pm 4.63 years (range: four months to 16 years), and half of them were $\leq 5$ years old (Table 1 ).

A total of 360 transfusions have been given; males had higher frequency of transfusions (59.7\%) than females (40.3\%). Age group 1-5 years old was most commonly encountered $(50 \%)$, and received the highest proportion (34.2\%) of transfusions, but the higher transfusion ratio (2.3/ patient) was noted in the age band 6-10 years old. Single transfusion was accounted for 204 (56.7\%) transfusion episodes, 2-4 in 156 (43.3\%), and five units or more in 43 (27.5\%) episodes.

Based on pediatric specialty wards, the hematology ward accounted for the largest number of blood transfusions $(60.8 \%)$, followed by oncology $(21.9 \%)$, and ICU $(7.5 \%)$. The highest transfusion rate (4.6/patient) was observed in the oncology ward, and the lowest rate $(1.7 \%)$ in the gastroenterology ward.

In our hospital, the main blood components used for transfusion are whole blood components (red cells and platelets); their distribution is shown in Table 2. The majority of transfusions were used for hematologic/ oncologic diseases. Hemoglobinopathies with its two main groups sickle cell disease (SCD) and ß-thalassemia were

Table I Distribution of Children and Transfusion Episodes by Age, Sex and Location

\begin{tabular}{|l|c|c|c|c|c|}
\hline \multirow{2}{*}{ Variables } & \multicolumn{2}{|c|}{$\begin{array}{c}\text { Children } \\
\text { (n=202) }\end{array}$} & \multicolumn{2}{c|}{$\begin{array}{c}\text { Transfusion } \\
\text { Episodes (n=360) }\end{array}$} & Ratio \\
\cline { 2 - 6 } & n & $\%$ & n & $\%$ & \\
\hline Age (years) & 32 & 15.8 & 45 & 12.5 & 1.4 \\
\hline$<1$ & 69 & 34.2 & 105 & 29.2 & 1.5 \\
I-5 & 47 & 23.3 & 109 & 30.3 & 2.3 \\
$6-10$ & 54 & 26.7 & 101 & 28.1 & 1.9 \\
II-16 & 128 & 63.4 & 215 & 59.7 & 1.7 \\
\hline Sex & 74 & 36.6 & 145 & 40.3 & 1.9 \\
\hline Male & \multicolumn{5}{|c|}{} \\
Female & 136 & 67.3 & 219 & 60.8 & 1.6 \\
\hline Location (ward) & 17 & 8.4 & 79 & 21.9 & 4.6 \\
\hline Hematology & 18 & 8.9 & 27 & 7.5 & 1.5 \\
Oncology & 13 & 6.4 & 16 & 4.4 & 1.2 \\
ICU & 12 & 5.9 & 13 & 3.6 & 1.1 \\
General & 6 & 3.0 & 6 & 1.7 & 1.0 \\
Isolation &
\end{tabular}


Table 2 Distribution of Blood Components by Indication

\begin{tabular}{|c|c|c|c|c|c|c|c|c|}
\hline \multirow[t]{2}{*}{ Indication } & \multicolumn{2}{|c|}{ RBC } & \multicolumn{2}{|c|}{ Whole Blood } & \multicolumn{2}{|c|}{ Platelets } & \multicolumn{2}{|c|}{ All } \\
\hline & $\mathbf{n}$ & $\%$ & $\mathbf{n}$ & $\%$ & $\mathbf{n}$ & $\%$ & $\mathbf{N}$ & $\%$ \\
\hline Hemoglobinopathies & 154 & 72.6 & 3 & 3.2 & - & - & 157 & 43.6 \\
\hline SCD & 110 & 51.9 & 3 & 3.2 & - & - & 113 & 31.3 \\
\hline Thalassemia & 44 & 20.8 & - & - & - & - & 44 & 12.2 \\
\hline Malignancies & 12 & 5.7 & 39 & $4 I .1$ & 40 & 76.9 & 91 & 25.3 \\
\hline Leukemias & 2 & 0.9 & 32 & 33.7 & 29 & 55.8 & 63 & 17.5 \\
\hline Solid tumors and lymphomas & 10 & 4.7 & 7 & 7.4 & II & 21.2 & 28 & 7.8 \\
\hline Impaired hematopoiesis ${ }^{b}$ & 22 & 10.4 & 18 & 18.9 & - & - & 41 & 11.3 \\
\hline Critically ill patient & 14 & 6.6 & 9 & 9.5 & I & 1.9 & 24 & 6.7 \\
\hline Visceral leishmaniasis & 2 & 0.9 & 12 & 12.6 & 2 & 3.8 & 16 & 4.4 \\
\hline Malaria & 3 & 1.4 & 10 & 10.5 & I & 1.9 & 14 & 3.9 \\
\hline Bleeding disorders & I & 0.5 & 3 & 3.2 & 6 & 11.5 & 10 & 2.8 \\
\hline Others $^{\mathrm{a}}$ & 4 & 1.9 & I & I.I & 2 & 3.8 & 7 & 1.9 \\
\hline
\end{tabular}

Notes: ${ }^{a}$ Others; preoperative, active viral hepatitis, infectious mononucleosis, nephrotic syndrome. ${ }^{b}$ One case received fresh plasma.

the most common indication (43.6\%); (31.3\%) for SCD and $(12.2 \%)$ for $\beta$-thalassemia patients. Malignancies including leukemias, solid tumors and lymphomas accounted for $(25.3 \%)$ of transfusion events; $17.5 \%$ for leukemias and $7.8 \%$ for solid tumors and lymphomas. Impaired red cell synthesis was the indication for transfusion in 41 patients (11.3\%), encompassing 22 (6.1\%) patients with nutritional anemia, $12(3.3 \%)$ anemia resulted from bone marrow failure (BMF), four (1.1\%) anemia due to renal failure, and three $(0.8 \%)$ dyserythropoietic anemia. Critically ill patients in the ICU received $6.7 \%$ of total transfusions; they included patients with congenital heart disease (CHD), heart failure, respiratory infections, sepsis and meningoencephalitis. Visceral leishmaniasis was present in 16 patients (4.4\%), and malaria infection in 14 patients (3.9\% of transfusions). Bleeding problems occurred in 10 patients $(2.8 \%)$, including seven patients with acute and chronic immune thrombocytopenic purpura (ITP), and three patients had disseminated intravascular coagulation (DIC). The category of others included various reasons for transfusion, three cases were admitted for preoperative preparation, diagnosed with cervical abscess, posterior urethral valve and cystic hygroma. Infectious mononucleosis, nephrotic syndrome, and hepatitis A viral infection, one patient each.

For all red cell transfusions, doses were calculated in volume ( $\mathrm{mL} / \mathrm{kg}$ body weight), and the overall mean volume of prescribed blood was $13.2 \mathrm{~mL} / \mathrm{kg}$. A volume of $15 \mathrm{~mL} / \mathrm{kg}$ was usually prescribed with little variation by reason for transfusion and patient clinical status. Platelet transfusion was calculated as one unit/10 kg body weight. Red blood cell concentrate (RBCs) was the blood component more frequently transfused (58.9\%), followed by whole blood (26.4\%), and platelet concentrates (14.4\%), while fresh plasma (frozen/thawed) was only transfused once. RBCs were prescribed mainly for patients with chronic anemias to avoid volume overload.

All patients had documented pre-transfusion $\mathrm{Hb}$, with overall mean level $6.7 \pm 2.3 \mathrm{~g} / \mathrm{dL}$, and with no significant difference between male and female $(6.6 \pm 2.3$ vs $6.8 \pm 2.3 \mathrm{~g} /$ $\mathrm{dL}, p=0.351$ respectively). Evidently, the average pretransfusion $\mathrm{Hb}$ was significantly lower in patients receiving RBC compared to patient needing platelets transfusion ( $\mathrm{Hb} 6.1 \pm 20$ vs $9.8 \pm 1.5 \mathrm{~g} / \mathrm{dL}, p<0.001$ respectively), where the average pre-transfusion platelets was significantly lower in platelets transfused patients than in $\mathrm{RBC} /$ whole blood transfused patients, with median (IQR) 14.0 (8.25-$28.0)$ vs $163.5 \quad(79.25-315.75)\left(1000 / \mathrm{mm}^{3}\right) \quad(p<0.001)$. About one quarter of patients had profound anemia with pre-transfusion $\mathrm{Hb}$ levels less than $5 \mathrm{~g} / \mathrm{dL}$, while $64.7 \%$ between 5 and $10 \mathrm{~g} / \mathrm{dL}$, and $10.3 \%$ more than $>10 \mathrm{~g} / \mathrm{dL}$. In hemoglobinopathies, malaria, visceral leishmaniasis, and impaired erythropoiesis, the mean pre-transfusion $\mathrm{Hb}$ values were generally low, while in malignancies and bleeding disorders the mean pre-transfusion $\mathrm{Hb}$ levels were decreased but not that much. The average pretransfusion platelet count was low in malignancies $43.619 \pm 65.24\left(1000 / \mathrm{mm}^{3}\right)$, but it was even lower 29.800 $\pm 49.87\left(1000 / \mathrm{mm}^{3}\right)$ in cases with bleeding disorders (Table 3). 
Table 3 Pre-transfusion Hb Levels and Platelets Count by Indication

\begin{tabular}{|c|c|c|c|c|}
\hline \multirow[t]{2}{*}{ Indication } & \multicolumn{2}{|c|}{ RBC Transfusions } & \multicolumn{2}{|c|}{ Platelets Transfusions } \\
\hline & $\mathrm{Hb}(\mathrm{g} / \mathrm{dL})$ & Platelets $\left(10^{3} / \mathrm{mm}^{3}\right)$ & $\mathrm{Hb}(\mathrm{g} / \mathrm{dL})$ & Platelets $\left(10^{3} / \mathrm{mm}^{3}\right)$ \\
\hline \multicolumn{5}{|l|}{ Hemoglobinopathies } \\
\hline SCD & $5.15 \pm 1.32$ & $281.58 \pm 169.38$ & - & - \\
\hline Thalassemia & $6.95 \pm 0.86$ & $320.57 \pm 175.28$ & - & - \\
\hline \multicolumn{5}{|l|}{ Malignancies } \\
\hline Leukemias & $7.7 I \pm 2.11$ & $45.23 \pm 38.19$ & $9.70 \pm 1.50$ & $27.32 \pm 33.44$ \\
\hline Solid tumors and lymphomas & $6.61 \pm 1.71$ & $202.24 \pm 234.23$ & $9.45 \pm 1.31$ & $17.24 \pm 10.47$ \\
\hline Impaired hematopoiesis & $5.33 \pm 2.55$ & $223.56 \pm 203.94$ & - & - \\
\hline Critically ill patient & $7.88 \pm 2.40$ & $234.78 \pm 149.18$ & $9.50 \pm 9.50$ & $14.00 \pm 14.00$ \\
\hline Visceral leishmaniasis & $5.97 \pm 1.19$ & $99.93 \pm 90.15$ & $9.85 \pm 0.8$ & $15.00 \pm 18.38$ \\
\hline Malaria & $5.88 \pm 1.64$ & $129.62 \pm 167.28$ & $8.00 \pm 8.00$ & $10.00 \pm 10.00$ \\
\hline Bleeding disorders & $5.93 \pm 0.79$ & $110.75 \pm 74.24$ & $11.90 \pm 0.75$ & $5.17 \pm 2.17$ \\
\hline Others $^{\mathrm{a}}$ & $7.48 \pm 0.95$ & $332.50 \pm 189.02$ & $8.35 \pm 1.80$ & $36.50 \pm 30.4 \mathrm{I}$ \\
\hline
\end{tabular}

Notes: ${ }^{a}$ Others; preoperative, active viral hepatitis, infectious mononucleosis, nephrotic syndrome.

Assessment of nutritional status based on weight for age, revealed underweight in $40.9 \%$ of children. However, differences in average pre-transfusion $\mathrm{Hb}$ between those with normal body weight and those with underweight was not statistically significance $(6.09 \pm 1.9$ vs $6.3 \pm 2.2 \mathrm{~g} / \mathrm{dL}$, $p=0.33$ respectively).

Post-transfusion $\mathrm{Hb}$ was only available for $59.2 \%$ of patients, and assessment of transfusion efficacy was calculated by differences between pre- and post-transfusion $\mathrm{Hb}$. The average $\mathrm{Hb}$ increment was found to be $1.4 \mathrm{~g} / \mathrm{dL}$, reflecting modest increment effect of blood transfusion. Absence of post-transfusion $\mathrm{Hb}$ was observed in 147 (40.8\%) patients, mainly for patients on a chronic transfusion program who left the hospital immediately after transfusions were completed.

The prevalence of the $\mathrm{ABO} / \mathrm{Rhesus} \mathrm{D}$ blood groups in the study population were: $\mathrm{O}$ positive $55.4 \%$, A positive $22.8 \%$, A negative $7.4 \%$, B positive $7.4 \%$, O negative $4 \%$, $\mathrm{AB}$ positive $2 \%$, $\mathrm{AB}$ negative (1\%). All blood group types were requested in this study except blood group B negative. In total, $88 \%$ were Rhesus D positive, and (12\%) were Rhesus D negative. The most requested group was $\mathrm{O}$ positive $(57.5 \%)$, followed by A positive $(21.9 \%)$, and the least requested blood type was $\mathrm{AB}$ negative $(0.6 \%)$.

Among 360 transfusions, acute adverse transfusion reactions (ATRs) occurred in 16 events $(4.4 \%)$, including febrile nonhemolytic $(56.2 \%)$, allergic $(37.5 \%)$ and transfusion associated dyspnea (TAD) $(6.3 \%)$. The median age of children with ATRs was five years (IQR: 0.8-10.0), and males showed more transfusion reactions $(62.5 \%)$ than females $(37.5 \%)$. All reactions were of minor type and fully controlled with complete patient recovery.

Of the 202 children, 25 (12.4\%) died during the study period (Table 4). Deaths were attributed to the underlying primary diseases and not directly related to the transfusion process. Higher proportions of death cases were observed in the younger age group $<1$ year $13 / 25(40.6 \%)$ and among female patients $15 / 25$ (60.0\%).

\section{Discussion}

This study is probably the first attempt to evaluate blood transfusion in pediatric patients in Yemen. The transfusion rate of $8.8 \%$ in this study is comparable to the $12.3 \%$ from Ghana, ${ }^{16}$ but lower than $16 \%$ in Tanzanian children, ${ }^{17}$ and $41.2 \%$ reported from southeast Nigeria. ${ }^{18}$ Higher frequency of blood transfusion in African countries could be explained by the high prevalence of severe childhood anemia complicating malaria infections and lack of standard blood transfusion protocols.

The current study showed a higher frequency of blood transfusion in male children $(63.4 \%)$ than female $(36.6 \%)$, which is similar to the $63.1 \%$ and $36.9 \%$ reported by Orish et $\mathrm{al}^{16}$ from Ghana. However, in developed countries gender differences are not prominent. In a multicenter study from England, 57\% of transfused children were males, ${ }^{19}$ while a multi-institutional analysis in the USA, male and female were almost equally transfused. ${ }^{20}$ It is not clear 
Table 4 Clinical Outcomes of Transfused Children

\begin{tabular}{|c|c|c|c|c|c|c|}
\hline \multirow[t]{2}{*}{ Variables } & \multicolumn{2}{|c|}{$\begin{array}{c}\text { All, } \\
\mathrm{n}=202\end{array}$} & \multicolumn{2}{|c|}{$\begin{array}{l}\text { Alive, } \\
\mathrm{n}=177\end{array}$} & \multicolumn{2}{|c|}{$\begin{array}{c}\text { Dead, } \\
n=25\end{array}$} \\
\hline & $\mathbf{n}$ & $\%$ & $\mathbf{n}$ & $\%$ & $\mathbf{n}$ & $\%$ \\
\hline \multicolumn{7}{|l|}{ Sex } \\
\hline Male & 128 & 63.4 & 118 & 92.2 & 10 & 7.8 \\
\hline Female & 74 & 36.6 & 59 & 79.7 & 15 & 20.3 \\
\hline \multicolumn{7}{|l|}{ Age group (years) } \\
\hline$<1$ & 32 & 15.8 & 19 & 59.4 & 13 & 40.6 \\
\hline $1-5$ & 69 & 34.2 & 62 & 89.9 & 7 & 10.1 \\
\hline $6-10$ & 47 & 23.3 & 44 & 93.6 & 3 & 6.4 \\
\hline $11-16$ & 54 & 26.7 & 52 & 96.3 & 2 & 3.7 \\
\hline \multicolumn{7}{|l|}{ Indications } \\
\hline Hemoglobinopathies & 100 & 49.5 & 100 & 100 & 0 & 0 \\
\hline Malignancies & 23 & 11.4 & 18 & 78.3 & 5 & 21.7 \\
\hline Impaired hematopoiesis & 8 & 4.0 & 3 & 37.5 & 5 & 62.5 \\
\hline Critically ill patient & 24 & 11.9 & 16 & 66.7 & 8 & 33.3 \\
\hline Visceral leishmaniasis & 16 & 7.9 & 12 & 75.0 & 4 & 25 \\
\hline Malaria & 14 & 6.9 & II & 78.6 & 3 & 21.4 \\
\hline Bleeding disorders & 10 & 5.0 & 10 & 100 & 0 & 0 \\
\hline Others & 7 & 3.5 & 7 & 100 & 0 & 0 \\
\hline \multicolumn{7}{|l|}{ Nutritional status } \\
\hline Normal weight & 75 & 37.1 & 67 & 89.3 & 8 & 10.7 \\
\hline Underweight & 127 & 62.9 & 110 & 86.6 & 17 & 13.4 \\
\hline
\end{tabular}

why male children received blood transfusions more frequently; this issue has not been adequately studied. However, in our sample it might be related to overrepresentation of males.

The mean age of transfused children in this study was $5.63 \pm 4.63$ years, which is comparable to $5.5 \pm 5.9$ years reported in a study from the USA, ${ }^{20}$ but higher than the median age 1.8 years reported from Tanzania, where malarial anemia in infants is the main trigger for transfusion. ${ }^{17}$ Children aged $1-5$ years were the major group of transfusion recipients and this might be attributed to prevalent hemoglobinopathies and nutritional deficiencies in the children under five, a common finding in developing countries, including Yemen. ${ }^{21}$

The hematology ward transfused the largest number of blood products $(60.8 \%)$, followed by oncology $(21.9 \%)$, which is comparable to results obtained from a study in Uganda, where $74 \%$ of blood was consumed in the hematology ward, ${ }^{22}$ and consistent to that reported from the UK by New et al, ${ }^{23}$ who found more than half (53\%) of recipients with a hematologic and oncologic underlying diagnosis. In the present study, the intensive care unit showed a low transfusion rate $(7.5 \%)$ which is comparable to that reported by others. ${ }^{24,25}$ Transfusion of critically ill patients might expose them to transfusion related risks without clear benefits. ${ }^{24}$ Furthermore, critically ill children transfused for other indications than anemia have worse outcomes than those not transfused with a similar degree of anemia. ${ }^{26}$

Most patients $(56.7 \%)$ received only a single blood transfusion, indicating that acute anemia was the most common reason for blood transfusion, this finding is comparable to reports from Venezuela $(86.4 \%),{ }^{27}$ UK $(74 \%),{ }^{23}$ and USA (69\%). ${ }^{20}$ Repeated transfusions may increase the risk of alloimmunization, particularly in sickle cell disease and thalassemia patients, therefore extended blood group sub-typing is strongly recommended. ${ }^{12}$

In this study SCD and $\beta$-thalassemia were the most common indications for blood transfusion, consistent with findings of other researchers. ${ }^{20,23}$ However, in spite of high prevalence of hemoglobinopathies in Sub-Saharan Africa, malaria-associated anemia did surpass other causes. Malignancies were the second most common indication for blood transfusion in this study $(25.3 \%)$, a result similar to $27.4 \%$ and $31.7 \%$ in Uganda and Nigeria studies, respectively. ${ }^{18,22}$

Pre-transfusion $\mathrm{Hb}$ was asked for all patients in this study in contrast to the reports from Tanzania and Uganda, where in $35 \%$ and $30 \%$ of patients pretransfusion $\mathrm{Hb}$ has not been measured. ${ }^{17,28}$ This can be attributed to urgent needs for transfusion in trauma and surgery as well as the availability and accessibility of hospital laboratory services. There was a wide variation in $\mathrm{Hb}$ values prior to blood transfusion with a mean of 6.7 g/dL (range: 1.6-13.1 g/dL). A similar result was reported by a Kenyan study, where median pretransfusion $\mathrm{Hb}$ was $6.0 \mathrm{~g} / \mathrm{dL}$ (IQR: $4.2-9.1 \mathrm{~g} / \mathrm{dL}$ ). ${ }^{29}$ Profound anemia with pre-transfusion $\mathrm{Hb}<5 \mathrm{~g} / \mathrm{dL}$ was detected in $25 \%$ of our patients, which is lower than $46.9 \%$ and $35 \%$ reported from Ghana and Congo, respectively, ${ }^{16,25}$ but higher than $15.2 \%$ reported in Nigerian children. ${ }^{18}$ Transfused children with pretransfusion $\mathrm{Hb}$ of $\geq 7 \mathrm{~g} / \mathrm{dL}$ were commonly cases with oncologic diseases and were often transfused at multiple times to build up their $\mathrm{Hb}$ concentration and to correct thrombocytopenia as a prerequisite for cytotoxic medications. In addition, $\beta$-thalassemia patients are regularly transfusion to keep their $\mathrm{Hb}$ levels at about 9-10 g/dL. All children with pre-transfusion $\mathrm{Hb}>10 \mathrm{~g} / \mathrm{dL}$ received 
only platelets transfusions because of thrombocytopenia without anemia.

In the present study the mean $\mathrm{Hb}$ increment was $1.4 \mathrm{~g} /$ $\mathrm{dL}$, this finding is situated at the lower quartile of that reported from the UK $2.8 \mathrm{~g} / \mathrm{dL}$ (IQR: $1.4-3.9 \mathrm{~g} / \mathrm{dL}){ }^{23}$ and comparable to $1.3 \mathrm{~g} / \mathrm{dL}$ reported by a Kenyan study, ${ }^{30}$ but less than $3.1 \mathrm{~g} / \mathrm{dL}$ reported from Nigeria. ${ }^{18}$ Variation in $\mathrm{Hb}$ increases may be affected by storage time and Hct level of donated blood, and it may also reflect different blood volume calculation especially in communities with high prevalence of underweight and absence of a standard blood transfusion protocol.

$\mathrm{ABO}$ and Rhesus $\mathrm{D}$ blood grouping showed $\mathrm{O}$ positive was the most commonly requested group, followed by A positive then $B$ group and the least requested is $A B$ blood group. The distribution of $\mathrm{ABO}$ and $\mathrm{Rh}$ blood typing of our patients are in concordance to the distribution of these groups in the local community. ${ }^{31}$

In this study $\mathrm{RBC}$ was prescribed more than any other blood products $(58.9 \%)$, similar to $60.2 \%$ reported in the $\mathrm{USA}^{20}$ and $52.7 \%$ reported in Venezuelan children, ${ }^{27}$ but different to that reported in southeast Nigeria where whole blood (56.4\%) was most transfused. ${ }^{18}$ Patients with chronic hemolytic anemias may require recurrent transfusions with red cell concentrate to ameliorate the complications associated with the disease, therefore, using more RBCs can be explained by the presence of higher proportion of children with chronic hemolytic anemias, which mostly required frequent and repeated transfusions with greater precaution about the risk of hypervolemia.

Malignancies were top ranked in platelet use accounting for $(76.9 \%)$, and they were transfused mostly as prophylaxis to increase low platelet counts and decrease the risk of bleeding. This result is comparable to that found in Iran, ${ }^{32}$ where more than $80 \%$ of platelet units were transfused to patients who had malignancies with thrombocytopenia, and similar to the finding in Spain where $67 \%$ of platelet transfusions were given for bleeding prophylaxis in thrombocytopenic patients. ${ }^{33}$

Adverse reaction to blood transfusions vary from a simple episode of fever to life-threatening hemolysis, and although they likely remain underdiagnosed, they are generally reported in children twice more than adults and in males more than females. ${ }^{2}$ In this study, a total of 16 blood transfusion reactions (4.4\%) was observed, a frequency comparable to that reported by a Brazilian study $3.8 \%,{ }^{34}$ but lower than $11.6 \%$ in India, ${ }^{35}$ and higher than $0.17 \%$ in the $\mathrm{USA}^{36}$ and $0.9 \%$ in the UK. ${ }^{19}$ The most common type of transfusion reaction was febrile nonhemolytic transfusion reaction (FNHTR) 56.2\%, a result in close similarity to $60 \%$ reported by Gauvin et al, ${ }^{37}$ (Canada) in pediatric ICU and to $45 \%$ reported in an Indian study, ${ }^{35}$ but different from the Brazilian study where allergic reactions were most commonly reported $(77.2 \%){ }^{34}$ FNHTR can be significantly reduced by prestorage leukoreduction of donor blood, but this is not available in our hospital due to financial constraints.

Regarding the blood product involved in transfusion reactions, in this study RBCs was the most frequently reported product $(66.7 \%)$; this might be attributed to higher use of this component mainly for children with chronic hemolytic anemias. This result is comparable to $53.8 \%$ in the $\mathrm{UK}^{20}{ }^{20}$ and $82.8 \%$ in India, ${ }^{35}$ but in contrast to a Brazilian study which found $50.9 \%$ of transfusion reactions in platelet transfusions. ${ }^{34}$ Recipients with recurrent blood transfusions in the present study had higher rate of ATRs (62.5\%) and allergic transfusion reaction is mostly prevalent in those repeatedly transfused, this result is similar to previous studies from the $\mathrm{USA}^{20}$ and India. ${ }^{35}$ However, with lack of standard definitions and uniform criteria for diagnosis of ATRs in children, comparisons between studies are difficult owing to variations in sample size, age, study method and duration, transfusion indications, availability of safe blood and blood products and presence of patient blood management and hemovigilance programs. $^{2}$

There were 25 deaths amongst the 202 children in this study giving a mortality rate of $12.4 \%$, which was higher than $9 \%$ reported in Kenyan children, ${ }^{38} 5.1 \%$ in Malawi, ${ }^{30}$ $5.6 \%$ in Congo, ${ }^{25}$ and $8.2 \%$ in Tanzania. ${ }^{17}$ Deaths here are not related to blood transfusion, but attributed to the underlying diseases and their complications. In this study death was noticed more in the younger age group $<1$ year and in female patients, which is comparable to the study conducted in Tanzania, where females were three times more likely to die compared to males. ${ }^{17}$

The current study provides an insight into transfusion pattern and recipient characteristics in pediatric patients living in limited resource settings (poor economics). However, patterns of blood transfusion vary in different localities; depending on specific disease prevalence, patient comorbidities, clinical experience, availability of safe blood, efficiency of blood transfusion services and the overall development of the health-care system in a country.

The main limitation of this study was that it was conducted in a single center and the findings may be different 
in other hospitals. Although our hospital serves a wide geographical catchment area with many referrals, because of the lack of local comparable data we do not know if current data truly reflect the overall transfusion pattern in other similar health facilities or in the country as a whole. A multicenter survey is recommended that can provide more data and solid conclusions. The study did not include details about storage time of donated blood and hematocrit levels, which might have some influence on the transfusion outcomes and $\mathrm{Hb}$ increments. Owing to lack of facilities for blood components separation at our institute, there was apparent underutilization of fresh plasma and cryoprecipitate, and occasionally fresh blood was used instead of specific components.

Based on the findings of this study, assessment of patient outcomes at times of blood shortage or utilization of new technologies such as pathogen reduction are recommended.

\section{Conclusions}

Blood transfusion is a frequent supportive therapy in pediatric patients with various medical illnesses in this population. Hemoglobinopathies and oncologic diseases were the most common indications for blood transfusion. Among the utilized blood components, red blood cell concentrate was the most frequently prescribed, followed by whole blood. Blood group $\mathrm{O}$ positive was the most commonly requested group. Adverse transfusion reactions were of mild type and febrile nonhemolytic reactions were commonly encountered. The findings of this study highlight the importance of regular review and documentation of blood transfusion practice to ensure better and more rational use of this precious resource.

\section{Disclosure}

The authors report no conflicts of interest with respect to the research, authorship, and/or publication of this article.

\section{References}

1. Goodnough LT, Panigrahi AK. Blood transfusion therapy. Med Clin North Am. 2017;101(2):431-447. doi:10.1016/j.mcna.2016.09.012

2. Moncharmont $P$. Adverse transfusion reactions in transfused children. Transfus Clin Biol. 2019;26(4):329-335. doi:10.1016/j.tracli.2019.08. 002

3. Klein HG. Should blood be an essential medicine? $N$ Engl J Med. 2013;368(3):199-201. doi:10.1056/NEJMp1213134

4. World Health Organization. World Health Organization Model List of Essential Medicines: 21st List 2019. Geneva: World Health Organization; 2019.

5. World Health Organization. Global Status Report on Blood Safety and Availability 2016. Geneva: World Health Organization; 2017.
6. Custer B, Zou S, Glynn SA, et al. Addressing gaps in international blood availability and transfusion safety in low- and middle-income countries: a NHLBI workshop. Transfusion. 2018;58(5):1307-1317. doi: $10.1111 /$ trf.14598

7. World Health Organization. The Regional Status Report on Blood Safety and Availability, 2016. Cairo: EMRO; 2017.

8. Roberts N, James S, Delaney M, Fitzmaurice C. The global need and availability of blood products: a modelling study. Lancet Haematol. 2019;6(12):e606-e615. doi:10.1016/S2352-3026(19)30200-5

9. Haddad A, Benajiba M, Hmida S, et al. How to manage transfusion systems in developing countries: the experience of Eastern and Southern Mediterranean countries. Transfus Med. 2020;30(1):7-15. doi:10.1111/tme. 12663

10. Roberts DJ, Field S, Delaney M, Bates I. Problems and approaches for blood transfusion in the developing countries. Hematol Oncol Clin North Am. 2016;30(2):477-495. doi:10.10 16/j.hoc.2015.11.011

11. Hassell OBI, Maitland K. Blood transfusion in resource-limited settings. In: Hunter's Tropical Medicine. 9th ed. London: Magill Maguire - Ryan - Solomon; 2012:162-167.

12. McCormick M, Delaney M. Transfusion support: considerations in pediatric populations. Semin Hematol. 2020;57:65-72. doi:10.1053/j. seminhematol.2020.07.003

13. Goel R, Cushing MM, Tobian AA. Pediatric patient blood management programs: not just transfusing little adults. Transfus Med Rev. 2016;30(4):235-241. doi:10.1016/j.tmrv.2016.07.004

14. Rai PKS, Agrawal A. Unique aspects of red blood cell transfusion in pediatric patients. Int J Clinl Transfus Med. 2016;4:43-54.

15. Burnouf T. Blood products: unmet needs for essential medicines. Lancet Haematol. 2019;6(12):e598-e599. doi:10.1016/S2352-3026 (19)30217-0

16. Orish VN, Ilechie A, Combey T, Onyeabor OS, Okorie C, Sanyaolu AO. Evaluation of blood transfusions in anemic children in Effia Nkwanta Regional Hospital, Sekondi-Takoradi, Ghana. Am J Trop Med Hyg. 2016;94(3):691-694. doi:10.4269/ ajtmh.15-0310

17. Mosha D, Poulsen A, Reyburn H, Kituma E, Mtei F, Bygbjerg IC. Quality of paediatric blood transfusions in two district hospitals in Tanzania: a cross-sectional hospital based study. BMC Pediatr. 2009;9:51. doi:10.1186/1471-2431-1189-1151

18. Ughasoro MD, Ikefuna AN, Emodi IJ, Ibeziako SN, Nwose SO. Audit of blood transfusion practices in the paediatric medical ward of a Tertiary Hospital in Southeast Nigeria. East Afr Med J. 2013;90 (1):5-11.

19. Morley SL, Hudson CL, Llewelyn CA, et al. Transfusion in children: epidemiology and 10-year survival of transfusion recipients. Transfus Med. 2016;26(2):111-117. doi:10.1111/tme.12283

20. Slonim AD, Joseph JG, Turenne WM, Sharangpani A, Luban NL. Blood transfusions in children: a multi-institutional analysis of practices and complications. Transfusion. 2008;48(1):73-80. doi:10.1111/ j.1537-2995.2007.01484.x

21. Al-Sadeeq AH, Bukair AZ, Al-Saqladi AM. Assessment of undernutrition using composite index of anthropometric failure among children aged $<5$ years in rural Yemen. East Mediterr Health $J$. 2019;24(12):1119-1126. doi:10.26719/2018.24.12.1119

22. Butler EK, Hume H, Birungi I, et al. Blood utilization at a national referral hospital in sub-Saharan Africa. Transfusion. 2015;55 (5):1058-1066. doi:10.1111/trf.13010

23. New HV, Grant-Casey J, Lowe D, Kelleher A, Hennem S, Stanworth SJ. Red blood cell transfusion practice in children: current status and areas for improvement? A study of the use of red blood cell transfusions in children and infants. Transfusion. 2014;54 (1):119-127. doi:10.1111/trf.12313

24. Bahadur S, Sethi N, Pahuja S, Pathak C, Jain M. Audit of pediatric transfusion practices in a tertiary care hospital. Indian J Pediatr. 2015;82(4):333-339. doi:10.1007/s12098-014-1370-2 
25. Mueller Y, Bastard M, Ehounou G, et al. Effectiveness of blood transfusions and risk factors for mortality in children aged from 1 month to 4 years at the Bon Marche Hospital, Bunia, Democratic Republic of the Congo. Trop Med Int Health. 2012;17 (12):1457-1464. doi:10.1111/j.1365-3156.2012.03095.x

26. Markham C, Small S, Hovmand P, Doctor A. Transfusion decision making in pediatric critical illness. Pediatr Clin North Am. 2017;64 (5):991-1015. doi:10.1016/j.pcl.2017.06.003

27. Marti-Carvajal AJMNS, Martí-Pena AJ, Matheus-Fernandéz E, Medina-Laurentin MC. Appropriate use of blood products in pediatric patients in a Venezuelan general university hospital: cross sectional study. Salus. 2005;9(1):20-30.

28. Natukunda B, Schonewille H, Smit Sibinga CT. Assessment of the clinical transfusion practice at a regional referral hospital in Uganda. Transfus Med. 2010;20(3):134-139. doi:10.1111/j.13653148.2010.00992.x

29. Nabwera HM, Fegan G, Shavadia J, et al. Pediatric blood transfusion practices at a regional referral hospital in Kenya. Transfusion. 2016;56(11):2732-2738. doi:10.1111/trf.13774

30. Cheema B, Molyneux EM, Emmanuel JC, et al. Development and evaluation of a new paediatric blood transfusion protocol for Africa. Transfus Med. 2010;20(3):140-151. doi:10.1111/j.13653148.2010.00989.x

31. Mohsen MM, Gamal AH, Abood AM. Prevalence of blood groups in Aden population. Univ Aden J Natl Appl Sci. 1998;3(2):147-152.
32. Javadzadeh Shahshahani HHH, Meraat N, Savabieh S, Savabieh S. Epidemiology of blood component recipients in hospitals of Yazd, Iran. Transfus Med. 2015;25(1):2-7. doi:10.1111/tme.12170

33. Bosch MA, Contreras E, Madoz P, et al. The epidemiology of blood component transfusion in Catalonia, Northeastern Spain. Transfusion. 2011;51(1):105-116. doi:10.1111/j.1537-2995.2010.02785.x

34. Pedrosa AK, Pinto FJ, Lins LD, Deus GM. Blood transfusion reactions in children: associated factors. J Pediatr (Rio J). 2013;89 (4):400-406. doi:10.1016/j.jped.2012.12.009

35. Ghataliya KJ, Kapadia JD, Desai MK, et al. Transfusion-related adverse reactions in pediatric and surgical patients at a tertiary care teaching hospital in India. Asian J Transfus Sci. 2017;11(2):180-187. doi:10.4103/0973-6247.214348

36. Berg A, Courtney R, Krishnamurti L, Triulzi DJ, Yazer MH. Is intensive monitoring during the first transfusion in pediatric patients necessary? Hematology. 2014;19(5):304-308. doi:10.1179/16078 45413Y.0000000122

37. Gauvin F, Lacroix J, Robillard P, Lapointe H, Hume H. Acute transfusion reactions in the pediatric intensive care unit. Transfusion. 2006;46(11):1899-1908. doi:10.1111/j.1537-2995.20 06.00995.x

38. Berkley JA, Ross A, Mwangi I, et al. Prognostic indicators of early and late death in children admitted to district hospital in Kenya: cohort study. BMJ. 2003;326(7385):361. doi:10.1136/ bmj.326.7385.361
International Journal of Clinical Transfusion Medicine

\section{Publish your work in this journal}

International Journal of Clinical Transfusion Medicine is an international, peer-reviewed, open access, online journal publishing clinical-experimental, policy-making and evidence-based practices of all topics pertaining to clinical transfusion medicine. Original research, short reports, reviews, case reports and commentaries are invited.
The manuscript management system is completely online and includes a very quick and fair peer-review system, which is all easy to use. Visit http://www.dovepress.com/testimonials.php to read real quotes from published authors.. 